absorbing molecules in the molecular groupings, which other optical methods cannot indicate ; for the absorption due to one molecule is independent of that of a neighbouring molecule, while the phenomena of refraction only show resultant effects.

Further, as experiment shows that in most crystalline substances the principal directions of absorption coincide with the principal directions of optical elasticity, and as it is probably right to assume that each molecule is subject to the same laws as the whole of the crystal, there is no reason to suppose that the directions of symmetry should be different in the molecule and in the crystal, provided the latter presents no optical anomaly. One can therefore assume that the principal directions of absorption in the molecules themselves coincide with their axes of optical elasticity, and that in mixed crystals the anomalous directions of absorption indicate the direction of the optic axes of the different absorbing substances. If this is really the cause of the anomalies in the direction of certain bands, each group of anomalous bands ought to belong to different substances, of which the existence in the crystal is thus revealed.

To prove the truth of this beautiful theory, M. Becquerel points out the significant fact that among the substances which he finds to be characterized by anomalous bands, several have been separated chemically into their components.

We have, therefore, in the observation of anomalous directions of absorption a new method of spectral analysis, a method of determining in a crystal the presence of isomorphous substances, optically dissimilar. We can even go further still, and recognize the existence of different substances, although they may not manifest anomalous directions of absorption. For, suppose the same bands are noticed to occur in the spectra of several crystals; if in one of these crystals two bands become maxima or minima at the same time for the same direction of vibration, and if in another crystal one of them disappears for the direction which renders the other a maximum, one may conclude that the bands are due to two different molecules.

This new method of analysis appears to be specially suitable for use in unravelling the mystery of the constitution of the rare earths. If, as seems now almost certain, they consist of the oxides of a large number of elementary substances, the difficulty experienced in separating them points to the fact that these constituent oxides must resemble each other closely. It is therefore most probable that their salts will be isomorphous, and the crystals of these salts may consequertly be expected to give absorption spectra of great interest in the light of the foregoing theory. M. Becquerel has therefore subjected the crystalline salts of didymium to the test of experi. ment, with the important result that several substances have been detected which chemists have recently isolated chemically; and also new substances have been identified as constituents, of which chemical methods have not as yet revealed the presence.

It will be remembered that Auer von Welsbach, by fractional crystallization of the double nitrates of didymium and ammonium, obtained two solutions-one possessing a green colour, showing almost exclusively the three bands $\lambda=482,469$, and 445 , and which he termed praseodymium; the other a red solution, giving the other bands of the didymium mixture except $\lambda=475.5$, which received the name neodymium. The study of the absorption spectrum of crystals of sulphate of didymium now shows that the two groups $\lambda=483.6$ 482.2 and $\lambda=471.5-470$, which have anomalous directions to a remarkable extent, are characteristic of praseodymium, while most of the bands of neodymium have directions quite different. Again, on examining these same groups belonging to praseodymium in the crystals of double nitrate of didymium and potassium, it is noticed that the bands which appear to have the same principal directions in the sulphate have in the double nitrate directions quite different, characterizing two distinct substances. Later experiments by Demarçay have indeed shown the possibility of chemically isolating two constituents--one exhibiting the band $\lambda=$ 469 , the other giving the bands of praseodymium.

Hence the new method proves a most valuable test of the accuracy of chemical work. In multiplying the observations, $\dot{M}$. Becquerel concludes that didymium is, as expected, a mixture of a large number of substances, chemically different; among the identified constituents are almost all that have been already chemically isolated, and very probably others, notably one substance which is characterized by the band $\lambda=571^{\circ} 7$.

A remarkable confirmation of this new law of crystal absorption was obtained in the following way. When a crystal of the sulphate or nitrate of didymium is dissolved in water, the spectrum of absorption of the solution presents curious differences from that of the crystal. Certain bands have remained permanent, but others are displaced, and some have entirely disappeared. This is readily explained if one admits that the crystal consisted of a mixture of compounds unequally acted upon by water. The most interesting fact, however, is that the bands which manifest these variations are precisely those which in the crystal present the anomalies.

In conclusion, we see that by the employment of this new method of analysis we are enabled, without destroying the crystal, as is necessary in chemical analysis, to recognize the presence of different chemical molecules; and as we obtain three distinct spectra from the three directions of optical elasticity, the method is one of extreme sensibility. Every investigator likes to see his work confirmed, and in this most difficult field of the rare earths we cannot have too many confirmations. The more points of the compass from which we approach it the better, for we are sure then of surrounding and finally of grasping the truth itself, in all its grand simplicity.

A. E. Tutтon.

\section{THE NEW VEGETATION OF KRAKATÃO}

THE great volcanic eruption of Krakatao in August 1883 will be fresh in most memories. It was at one time reported that the island had totally disappeared, but this was not so. Previous to the eruption, however, it was covered with a luxuriant vegetation, no trace of which existed after the event.

Dr. M. Treub, the Director of the Botanic Garden at Buitenzorg, Java, when at Kew last year informed the writer that he had visited the island the previous year, and intended publishing the results of his botanical investigations. This he has now done, ${ }^{1}$ and as the derivation of insular floras is a subject of great interest to many persons, the substance of Dr. 'Ireub's communication deserves a place in NATURE.

The existing portion of Krakatao Island is about three miles across, and has the form of a mountain rising out of the sea. On one side it is nearly perpendicular almost to the summit of the peak, which has an altitude of about $2500 \mathrm{feet}$, and on the other it presents a steep slope. It is situated ten miles distant from the Island of Sibesie, the nearest point where there is terrestrial vegetation; twenty miles from Sumatra, and twenty-one miles from Java. Verlaten and Lang Islands, lying much nearer Krakatao, were utterly desolated and denuded of their vegetation by the great catastrophe, and were still absolutely bare in 1886 .

With regard to the total destruction of vegetable life in the island, Dr. Treub asserts that there can be no doubt:

x. Annales du Jardin Botanizue de Buitenzors, vii. pp. 213-23, with a sketch map. 
the most durable seed and the best protected rhizome must have lost all vitality during the intense heat, and not a germ was left. The whole island from the summit of the peak down to the water's edge is now covered with a layer of cinders and pumice stone, varying from one to sixty metres in thickness. Furthermore, the possibility of the new vegetation having been conveyed thither by man is out of the question, because the island is uninhabited, uninhabitable, and difficult of access.

Therefore, the present vegetation must be due to other agencies, of which three different ones may have operated -namely, winds, waves, and birds.

Now, as to the composition of the vegetation met with on Krakatã by Dr. Treub in June I886, nearly three years after the eruption, the bulk consisted of ferns with isolated plants of Phanerogams, both on the shore and on the mountain itself. Eleven species of ferns were collected, and some of them were already common. They are all species of wide distribution, and it may be of interest to give their names: Gymnogramme calomelanos, Acrostichum scandens, Blechnum orientale, Acrostichum aureum, Pteris longifolia, Nephrolepis exaltatu, N'ephrodium calcaratum, N. flaccidum, Pteris aquilina, $P$. marginata, and Onychium auratum.

It is not at all surprising that the spores of the foregoing and many other ferns should have been carried to the island by winds; but, as Dr. Treub remarks, it is almost incomprehensible that they should grow under such extraordinarily disadvantageous conditions. Chemically and physically the volcanic matter covering the island is as sterile as could well be, yet the prothallia of ferns readily developed. A closer investigation, however, revealed the fact that ferns were not the first organisms in the new vegctation of Krakatao, the cinders and pumice-stone being almost everywhere covered with a thin coating of Cyanophycece (fresh-water Algæ) belonging to the genera Lyngbya, Tolypothrix, \&c.,--altogether six species. The presence of these Algæ gives the surface of the soil a gelatinous and hygroscopic property, in the absence of which Dr. Treub doubts the possibility of fern-growth. Thus these microscopic organisms prepare the soil for the ferns, much as the latter provide the conditions under which the seeds of Phanerogams can germinate and grow.

The phanerogamic element (flowering plants) of the new vegetation consisted, on the shore, of young plants of Calophyllum Inophyllum, Cerbera Odollam, Hernandia sonora, Scevola Kanigii, Ipomoa pes-capree, a species of Erythrina, two species of Cyperacee, and Gymnothrix elegans. With the exception of Gymnothrix elegans, a common grass in Java, all the plants named are among those which take possession of newly-raised coral islands.

In the interior of the island, on the mountain itself, Dr. Treub discovered Scavola Kanigii, Tournefortica argentea, a species of Wollastonia, a species of Senecio, two species of Conyza, Phragmites Roxburghii, and Gy'mnothrix elegans.

In addition to the foregoing Phanerogams, Dr. Treub observed on the sea-coast seeds or fruits of Heritiera littoralis, Terminalia Catappa, Cocos nucifera, Barringtonia speciosa, and Pandanus. These also are among the commonest sea-shore and coral island trees throughout the Malayan Archipelago and Polynesia.

A more interesting record of the processes of a new flora can hardly be imagined, especially that in relation to the preparation of the soil by microscopic sporiferous plants. Of course this is not a new discovery; but it is perhaps the first actual observation of the renewal of the vegetation of a volcanic island.

Dr. Treub intends visiting Krakatão again, and reporting fully on the progress of the new flora, and his report will doubtless belooked forward to with great interest.

W. B. Hemsley.

\section{THE NON-CHINESE RACES OF CHINA.}

A VALUABLE Report which has just been laid before Parliament contains an account of a journey made by Mr. Bourne, British Consular Agent at Chung-King in Szechuen province, through South-Western and Southern China, to study certain commercial questions in these regions. The journey lasted 193 days, and carried the traveller through the great provinces of Yunnan, Kwangsi, Kweichow, and Szechuen. Mr. Bourne was constantly brought into contact with various non-Chinese tribes inhabiting these provinces, and his Report contains a large amount of information respecting their language and habits. He also devotes a special appendix to them. He says that there is probably no family of the human race, certainly none with such claims to consideration, of which so little is accurately known as the non-Chinese races of Southern China, and he attributes this to the "perfect maze of senseless names" in which the subject has been involved by the Chinese. The "Topography of the Yunnan Province," published in 1836 , gives a catalogue of I4I classes of aborigines, each with a separate name and illustration, without any attempt to arrive at a broader classification. To Mr. Bourne it appeared that before the tribes could be scientifically assigned by ethnologists, they must be reduced to order amongst themselves, and that something might be done in this direction by taking a short vocabulary and obtaining its equivalent in the dialect of every tribe met with, when a comparison would reveal affinities and differences. Accordingly he gives twenty-two vocabularies, containing the numerals up to $12,20,30$, I00, 1000, father, mother, brother, sister, heaven, gold, hand, foot, sun, dog, horse, iron, \&c. -in all, thirty-six words. In each case the date, place, the name by which each tribe calls itself, the name by which the Chinese know it, and the name by which it knows the Chinese, is given. A comparison of these vocabularies and a study of Chinese books lead him to the conviction that, exclusive of the Tibetans, there are but three great non-Chinese races in Southern Chinathe Lolo, the Shan, and the Miao-tsze. The vocabularies do not convey the whole evidence that these scattered people respectively speak the same language, for the Lolo, Shan, and Miao-tsze are all languages of the Chinese type that make up .for poverty of sound by "tones"; the resemblance is much more striking to the ear accustomed to these distinctions of sound than when the words are written in English, when the similarity of tone is lost. Among the I4I tribes described in the Chinese topography of Yunnan, with short vocabularies of the principal dialects, there are very few, and those unimportant, that cannot be identified from the illustrations or letterpress as belonging to one or other of the three families or to Tibetan. As to the names of these families, Lolo is a Chinese corruption of Lulu, the name of a former chieftain of the people, who call themselves Nersu, and has come to stand for the people themselves. Shan is the Burmese term adopted by Europeans for the people who call themselves "Tai," "Pu-nong," \&c. Miao-tsze, a Chinese word, meaning "roots," is confined by the more accurate to the aborigines of Kweichow and Western Hunan.

The Lolos were formerly called by the Chinese the "Tsuan barbarians," a name taken from one of their chiefs. They call themselves Nersu, and the vocabularies show that they stretch in scattered communities as far as Ssu-mao, and along the whole southern border of Yunnan. They are also said by the Chinese to be found on the Burmese frontier. In a topography of Momien, a town not far from l3ahmo, in the extreme south-west of Yunnan, the following information is given about them, which is at least surprising:- "The old Tsuan (Lolo) of Mengshan do not die. When old, they grow tails, eat men, not distinguishing their own children, 